\title{
Applying threshold concepts to finance education
}

\author{
Abstract \\ Purpose: This study investigates and identifies threshold concepts that are the essential \\ conceptual content of finance programs. \\ Design/methodology/approach: Conducted in three stages with finance academics and \\ students, the study uses threshold concepts as both a theoretical framework and a research \\ methodology.
}

Findings: The study identifies ten threshold concepts in finance that are clearly endorsed by finance academics. However, the extent to which students are explicitly aware of the threshold concepts in finance is limited.

Research limitations/implications: As well as informing further research into the design and delivery of finance programs, the findings of the study inform the use of threshold concepts as a theoretical framework and a research methodology. The study does not explore the bounded, discursive, reconstitutive and liminal aspects of threshold concepts. Implications include the lack of recognition of more modern concepts in finance, and the need for input from industry and related disciplines.

Practical implications: The threshold concepts in finance provide the starting point for finance educators in the design and delivery of finance programs. In particular, the threshold concepts in finance need to be made more explicit to students.

Social implications: Using the threshold concepts in finance as well as the other findings of this study to inform to finance curriculum design and delivery is likely to achieve better quality educational outcomes for finance students as well as better prepare them for professional finance roles.

Originality/value: The finance curriculum is under researched and for the first time this study identifies the threshold concepts in finance to inform the design of finance programs.

\section{Keywords}

finance curriculum, students, faculty, mathematics, statistics, threshold concepts 


\section{Introduction}

This paper investigates the finance curriculum using threshold concepts as both a theoretical framework and a research methodology. The paper identifies the threshold concepts in finance, providing a base from which educators can construct and discuss with practitioners the essential conceptual content of finance programs. In addition, the research clarifies the role of interdisciplinary knowledge, primarily mathematics and statistics in finance, and in doing so informs approaches to developing this knowledge within finance programs.

Finance capabilities are essential in our society and in increasing demand, as indicated by industry trends and significant growth in student numbers. For example, enrolments in the specialist finance degree at one Australian University increased by over 200\% from 2002 to 2012, with a nearly 300\% increase in international students (Macquarie University, 2012). This demand is predicted to further increase as the finance industry sector increases in size (Deloitte, 2013). This expanding sector offers considerable employment opportunities for the increasing numbers of students who are undertaking finance programs.

As well as increasing in numbers, finance student cohorts are increasing in diversity as education becomes further globalised and international student numbers increase (Macquarie University, 2012). Prerequisite knowledge requirements have become more flexible, such as with the shift from "assumed" and "recommended" knowledge in Australia. At the same time, finance programs have to comply with multiple and multifaceted accreditation requirements, such as the Quality Assurance Agency for Higher Education in the UK, the Australian Securities and Investments Commission Regulatory Guide 146 and the Australian Qualifications Framework, and the US-based Chartered Financial Analyst Institute and Association to Advance Collegiate Schools of Business. Whilst this increased demand, diversity and accreditation are very positive for finance programs, it is even more essential that they are designed to meet the needs of students, employers and society more generally.

Like many disciplines, finance programs have developed organically resulting in a curriculum that is overcrowded and lacks coherence. However, research into what should be taught in finance programs is limited. This is in part due to the fact that finance was and continues to be taught within other disciplines, such as accounting and business. Thus, finance curriculum research tends to either focus on introductory finance rather than an entire finance program (eg Balachandran et al., 2006; Berry and Farragher, 1987; Cooley and Heck, 
1996; Gup, 1994; Krishnan et al., 1999) or on preparing students for specific professional roles (eg Jackling and Sullivan, 2007 - financial planners; Lakshmi, 2013 - accountants or chief financial officers; Roth et al., 2002 - entrepreneurs).

This study investigates the finance curriculum more broadly than previous research and conceptualises it in new and inspiring ways by identifying the transformational "threshold" concepts (Meyer and Land, 2003) in finance. The premise of threshold concepts is that in any discipline there are a limited number of concepts that are fundamental to mastery in the discipline (Cousin, 2006). “Understanding” a threshold concept involves passing through a conceptual gateway that "permits new and previously inaccessible ways of thinking and practising” (Land et al., 2014, p. 200). Threshold concepts are likely to engage students and involve deep learning because they transform the way students think and view the world. Thus, the identification of the threshold concepts in finance to inform the finance curriculum has the potential to achieve better quality educational outcomes for students as well as better prepare them for professional finance roles.

As originally conceptualised by Meyer and Land (2003), threshold concepts are, or are likely to be, transformative, integrative, irreversible, troublesome and/or bounded. In more recent literature, threshold concepts are increasingly also identified as discursive, reconstitutive and/or liminal (Barradell, 2013; Flanagan, 2015; Land et al., 2014). Due to the interdisciplinary nature of finance and the timing of the research, this study focuses on four of the original characteristics as follows:

1. Transformative - occasions a shift in the perception of the subject

2. Integrative - exposes the previously hidden interrelatedness of something

3. Irreversible - unlikely to be forgotten, or will only be unlearned by considerable effort

1.4.Troublesome - conceptually difficult and/or counter-intuitive (Meyer and Land, 2003).

Cousin (2009) identifies researching threshold concepts as a methodology for researching learning in higher education, involving collaboration with and participation by discipline specialists, educational specialists and learners. This study adopts this methodology, involving finance and educational specialists as researchers and finance specialists and students as participants, over three stages. In common with other threshold concepts research, data were collected using a range of methods and, as a result, different types of data were 
collected and analysed using a combination of qualitative and quantitative approaches and techniques. The overall research approach can be described as mixed methods (Johnson and Onwuegbuzie, 2004). This paper synthesises the findings of the three stages in relation to specific finance threshold concepts and also to inform the use of threshold concepts as both a theoretical framework and a research methodology. Separate reports of each stage that explore different aspects of the study are provided in [self-identifying citations removed].

The context of the research is two large finance programs (a specialist finance degree and a finance major) with a combined cohort of over 2,430 students taught at an Australian University. The programs have a strong international focus and a significant proportion of the students are international students. In addition, finance academics from institutions in five countries (Australia, Canada, New Zealand, South Africa and the United Kingdom) also participated in the research. The research investigates an internationalized finance curriculum and involves international participants and so informs the design of finance programs to prepare students for employment in the global finance industry.

The paper continues in the following sections with a review of the relevant finance curriculum and threshold concepts literature and then the methodology for the study is outlined. The results are presented and discussed together in a single section covering three areas: threshold concepts in finance, threshold concepts as a theoretical framework and threshold concepts as a research methodology. Finally, overall conclusions are drawn in relation to the study, and directions for future research are identified.

\section{Literature review}

Whilst some researchers refer to a body of literature in finance education (Balachandran et al., 2006; Krishnan et al., 1999; Lai et al., 2009) only a limited proportion of this research specifically investigates the finance curriculum; thus, as Lakshmi (2013) states, the area is under researched. Research that does specifically investigate the finance curriculum tend to focus on introductory finance rather than an entire specialist finance program, or on preparing students for specific professional roles. This is a result of the way finance has evolved from other disciplines. For example, the fact that finance was (and continues to be) taught within accounting programs that prepare students for the roles of accountants and chief financial officers has led to research into the finance curriculum required to prepare students for those roles. Notably, McWilliams and Pantalone (1994) investigate the entire finance curriculum; 
however, their research refers to subjects to be included in a finance program and so the findings are rather broad, for example investments and international finance.

In addition, previous research into the finance curriculum tends to focus on topics rather than concepts, although there is some slippageinconsistency in the use of the two terms (see Lai et al., 2009) as well asand overlap between finance concepts and finance topics in the literature. For example, many concepts identified by Gup (1994) are listed as topics by Cooley and Heck (1996) despite the fact that the latter does make the distinction between concepts and topics.

Interestingly, Gup argues that there is little agreement between executives and academics on the top five concepts in finance beyond present value. Although earlier research into the finance curriculum involved academics and executives as participants later research has involved students. Krishan et al. (1999) asked students to rank finance topics in order of importance whilst Balachandran et al. (2006) and Lai et al. (2009) asked students to rank finance concepts identified by Cooley and Heck (1996) in order of importance.

Notwithstanding, the different aims, scope and participants of previous finance curriculum research, there is a significant overlap between the findings. The finance topics and concepts identified in this previous research are summarized as follows:

- capital budgeting (techniques), internal rate of return

- capital structure

- capital asset pricing model

- financial statement analysis, cashflow and financial statements

- financial institutions and markets, capital markets, investment banking, investments

- risk and return

- time value of money, present value, present/future value annuity/single amount

- valuation, valuation theory, security valuation, valuing stocks/bonds, capital asset pricing model

- working capital (management), accounting.

An emphasis on the use of quantitative methods (Finance Learning Standards Working Party Australian Business Deans Council, 2014) has meant that finance has traditionally been considered to involve a significant amount of mathematics (and statistics as a type of 
mathematics) and indeed the financial services sector has been a major employer of mathematics graduates (Bourner et al., 2009).The role of mathematical modelling in financial services and the importance of understanding mathematical modelling in the context of the use of information systems (which tend to hide mathematical models) is discussed in the work of Bakker and Kent and their colleagues (Bakker et al., 2006; Kent et al., 2007).

However, Philippon and Reshef (2012) find that the extent to which finance roles involve mathematics varies, where greater regulation is associated with less mathematics in finance roles and vice versa. Further, behavioural finance, which acknowledges decision biases and non-rational behaviour, considers finance from a different perspective (Frankfurter 2006; Shiller 2006; Statman 2008), with less emphasis on quantitative methods (Coleman 2013).

Previous research specifically on threshold concepts in finance is restricted to the work of Diamond and Smith in relation to quantitative finance (Diamond, 2014; Diamond and Smith, 2011) and business statistics (Diamond, 2011). Diamond and Smith’s work on quantitative finance focuses on approaches to teaching threshold concepts, with five concepts suggested as examples: incomplete markets, Ito’s lemma, change of measure, risk neutrality, and cointegration analysis. In Diamond (2011), threshold concept theory is used as a framework to understand the nature of the content of the business statistics curriculum to explain surface versus deep learning. Diamond identifies eight examples of business statistics threshold concepts and maps these concepts using the three category framework developed by Davies and Mangan (2007). Whilst this research informs the current research to a certain extent, it is limited in scope to particular specialised sub-sections of the finance curriculum. The current research goes beyond Diamond's research to investigate threshold concepts in finance more broadly.

Given the limited amount of research specifically on threshold concepts in finance and the interdisciplinary nature of finance, with finance still commonly referred to as a sub-field of economics closely related to accounting (Finance Learning Standards Working Party Australian Business Deans Council, 2014) the literature on threshold concepts in economics is relevant to this study. Threshold concept theory was originally developed in relation to economics (Meyer and Land, 2003; 2005 for example) and Davies and Mangan (2005; 2007; 2008) propose a comprehensive range of examples of economics threshold concepts. Davis and Mangan (2007) also propose a three category framework that can be used to understand the threshold concepts in terms of the type of conceptual change they bring about, that is 
basic, discipline or procedural. According to Davies and Mangan, basic conceptual change involves replacing common sense, everyday understandings with discipline-specific ways of thinking; discipline conceptual change involves understanding and integrating concepts so that a discipline-specific perspective is developed; and procedural conceptual change is the ability to construct narratives and arguments in a discipline.

In summary, research into the finance curriculum is limited and partial; and even more so in relation to threshold concepts in finance-even more sø. There is literature on the role of mathematics and quantitative methods in finance-(more debated since the emergence of behavioural finance) and indeed, with much of the previous threshold concepts-research in relation to-on threshold concepts in finance-has focused on quantitative methods and business statistics. Notwithstanding this, the findings of previous research are a point of comparison for the current study. Given the close relationship between finance and economics, $\underline{\text { finance }}$ threshold concepts are likely to bring about similar typesthree categories of conceptual change (i.e. basic, discipline and procedural) as identified by Davies and Mangan (2007) in relation to economics threshold concepts - basic, discipline and procedural are likely to apply to threshold concepts in finance.

\section{Methodology}

The research was conducted in three stages as follows:

1. initial identification of finance threshold concepts by finance academics within the institution

2. verification of finance threshold concepts (identified in first stage) by finance academics beyond the institution and internationally

3. investigation of the extent to which students are aware of finance threshold concepts.

The three stages involved a range of methods; a combination of focus groups, interviews and questionnaires involving academics and students. Following Cousin's (2009) identification of the benefits of getting discipline specialists together to identify threshold concepts, focus groups were chosen as the most effective way to investigate staff and student perceptions of threshold concepts in finance. Questionnaires enabled the collection of data suitable for more quantitative analysis from finance academics beyond the institution and internationally and also from a greater number of students. 


\section{Stage 1}

An initial focus group was held with finance academics from within the institution and was attended by nine academics. A brief introduction to threshold concepts was given at the start of the focus group (Cousin, 2009) and the discussion was recorded and transcribed. The transcription was analysed linguistically using bottom-up and top-down approaches. The former involved identifying the nominal groups that represented proposals for threshold concepts in finance eg "short-selling”, "market efficiency". The latter involved using content (ie change of topic) and structural indicators (eg "Well”, "So") to identify distinct sections in the discussion (Halliday and Hasan, 1976; Matthiessen, 2004). The purpose of this was to gain an understanding of the (semantic) content of the entire discussion (Halliday and Matthiessen, 1999).

In addition to the staff focus groups, individual interviews were conducted with three key staff using a semi-structured format (Cousin, 2009). A brief introduction to threshold concepts was given at the start of each interview using a visual stimulus (Cousin, 2009) and the interviewees were asked to consider the threshold concept framework and to make proposals for threshold concepts in finance. Two of the interviews were recorded, transcribed and, as per the staff focus group, the proposals for threshold concepts identified. For the other interview, the interviewee provided a written summary of essential finance concepts.

The proposals for finance threshold concepts arising from the focus group and interviews were reviewed by the researchers individually and then as a group, to remove duplication and categorise them according to the framework developed by Davies and Mangan (2007), that is, basic, discipline and procedural. In addition, the proposals were categorised as finance concepts (e.g. "risk versus return") or statistics concepts (e.g. "expected value”).

\section{Stage 2}

An extended questionnaire was developed (self-identifying citation removed) and administered online to finance academics at multiple universities in Australia, Canada, New Zealand, South Africa and the United Kingdom. Forty-four responses were received. The questionnaire was used to verify whether the proposals for threshold concepts in finance identified in the first stage are threshold concepts and to investigate the applicability of the transformative, integrative, irreversible and troublesome characteristics of threshold concepts. An introduction to threshold concepts, explaining the four characteristics and using 
opportunity cost as an example from economics, was included in the questionnaire. Theand respondents were asked to nominate five threshold concepts themselves before seeing the proposals from stage 1 . The questionnaire was also used to investigate the general applicability of threshold concept theory to curriculum design and learning and teaching in finance.

The questionnaire consisted of mainly A combination of closed (including Likert scale); and short answer and openquestions, ${ }_{2}$ s. the Rresponses to which elosed, Likert seale and short answer questions-were analysed using quantitative techniques. The main open question was an optional question concerning the usefulness of threshold concept theory, particularly, the 4 characteristics (transformative, integrative, irreversible, troublesome), to learning and teaching in finance. $x$ Responses to this question were analysed by identifying the key themes, and also whether the response was positive, negative or neutral overall.

\section{Stage 3}

A short questionnaire seeking students' views as to the most important concepts in finance was administered to students at all levels (ie first, second, third and fourth year) of the two finance programs (self-identifying citation removed). This questionnaire was deliberately brief to encourage participation and so the threshold concept framework was not introduced or referred to. The key data collected by this questionnaire was student nominations for the three most important concepts in finance. Around 750 nominations for important concepts in finance were received. The nominations were categorised by the research team in relation to the findings of the research with finance academics, namely proposed threshold concepts, type of knowledge (Wood et al., 2012) and the role of modelling in finance. The categorisation was initially conducted by one member of the research team and then confirmed by two other members independently. Subsequent meetings were held between the

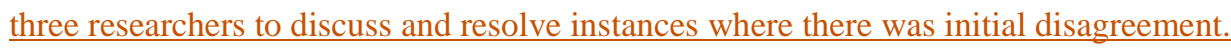

Quantitative techniques were used to summarise and interpret the results of the categorisation process.

\section{Results and discussion}

The first sub-section of this section synthesises and discusses the results of all three stage of the study in relation to the identification of threshold concepts in finance by academics and the extent to which students perceive the threshold concepts as important. The second and 
third sub-sections draw on the results to discuss the use of threshold concepts as a theoretical framework and as a research methodology respectively.

\section{Threshold concepts in finance}

The results of all three stages of the study in relation to threshold concepts in finance are collated in Table 1. The first section of Table 1 shows the 10 original proposals for threshold concepts by academics from a single institution (stage 1) that were clearly endorsed by academics from a number of institutions in different countries (stage 2). The second section shows the 12 concepts that were not clearly endorsed. And the third section of the table shows an additional seven concepts arising from the second stage of the study that have yet to be tested with finance academics. The concepts have been categorised as basic, discipline and procedural using the framework developed by Davies and Mangan (2007) and the distinction has been made between finance and statistics concepts, allowing the role of mathematics and statistics in finance to be more precisely described. The figures to the right of the concepts indicate the extent to which the concepts were evident in the 750 student nominations for important concepts in finance (stage 3). Column E shows the explicit student nominations of each concept (for example, "risk") and column $\mathrm{R}$ is the number of student nominations that were related to a threshold concept (for example, "contingent payments" categorised as relating to the threshold concept "risk"). These figures indicate the extent to which student understandings of what is important in finance overlap with the threshold concepts identified by academics.

Table 1. Threshold concepts in finance

\begin{tabular}{lllll}
\hline $\begin{array}{l}\text { Type of } \\
\text { conceptual change } \\
\text { (Davies and }\end{array}$ & Finance & & Statistics & \\
Mangan, 2007) & E & & & \\
\hline
\end{tabular}

Clearly Endorsed 


\begin{tabular}{|c|c|c|c|c|c|}
\hline \multirow[t]{2}{*}{ Basic } & $\begin{array}{l}\text { Information } \\
\text { asymmetry }\end{array}$ & - & 3 & Expected value & - \\
\hline & Risk versus return & 18 & 50 & & \\
\hline \multirow[t]{7}{*}{ Discipline } & Arbitrage & 7 & 9 & & \\
\hline & Diversification & 2 & 23 & & \\
\hline & Hedging & 9 & 5 & & \\
\hline & Market efficiency & $\underline{5} 3$ & - & & \\
\hline & Opportunity cost & 2 & 1 & & \\
\hline & Risk & 21 & 33 & & \\
\hline & Time value of money & 21 & 31 & & \\
\hline \multicolumn{6}{|c|}{ Not clearly endorsed } \\
\hline \multirow[t]{4}{*}{ Basic } & Leverage/gearing & 3 & 24 & Probability/randomness & - \\
\hline & $\begin{array}{l}\text { Markets and market } \\
\text { structure(s) }\end{array}$ & 4 & 96 & Time series & 1 \\
\hline & Pricing & - & 14 & & \\
\hline & Trade offs & - & - & & \\
\hline \multirow[t]{3}{*}{ Discipline } & Cashflows & 2 & 11 & $\begin{array}{l}\text { Central limit theorem } \\
\text { and normal distribution }\end{array}$ & - \\
\hline & Utility/risk preference & - & - & Correlation & - \\
\hline & & & & $\begin{array}{l}\text { Statistical significance } \\
\text { and hypothesis testing }\end{array}$ & \\
\hline Procedural & Modelling* & 6 & 13 & & \\
\hline \multicolumn{6}{|c|}{ Yet to be tested with academics } \\
\hline \multirow[t]{2}{*}{ Basic } & Liquidity & - & - & & \\
\hline & Valuation (value) & 19 & 54 & & \\
\hline \multirow[t]{5}{*}{ Discipline } & $\begin{array}{l}\text { Behavioural } \\
\text { finance** }\end{array}$ & 2 & 1 & & \\
\hline & Derivatives & 7 & 18 & & \\
\hline & $\begin{array}{l}\text { Principal-agent } \\
\text { problem }\end{array}$ & - & - & & \\
\hline & Marginal costs & - & - & & \\
\hline & Return & 9 & 59 & & \\
\hline Total & & 135 & 445 & & 1 \\
\hline
\end{tabular}

For finance educators the 10 clearly endorsed threshold concepts (Table 1) provide an important starting point for curriculum design around essential conceptual finance knowledge. In addition, finance educators can also consider the 12 concepts not clearly endorsed - particularly the basic concepts, which are possibly overlooked by finance academics due to their own experience and expertise, and the seven untested concepts particularly valuation (value) and return, which are strongly evident in the student data, and to a lesser extent, derivatives. 
The student data (shown in columns E and R brackets in Table 1) indicate that the extent to which students are explicitly aware of finance threshold concepts is inadequate, with only $18 \%$ of the 750 student nominations for important concepts in finance being threshold concepts but $60 \%$ of the student nominations being related to threshold concepts. (The remaining $22 \%$ of the student responses were either generic skills or too general/unclear to classify). Both the extent to which students are explicitly aware of threshold concepts and the extent to which the student nominations are related to threshold concepts can inform curriculum design and the way the concept is taught. Where the research indicates students are not aware of a threshold concept or are only aware of content related to a threshold concept, there is potential to put more emphasis on the concept and teach it more explicitly and in different ways to develop student awareness and understanding.

Importantly, statistics concepts, with the exception of expected value, are not clearly endorsed as threshold concepts by academics and are not to be evident in the student nominations. Modelling plays an integral role in finance in defining concepts and as the procedural knowledge (Wood et al., 2012) to construct discipline-specific narratives and arguments (Davies and Mangan, 2007). Despite this, and despite being implied in other concepts such as the time value of money, pricing and valuation, modelling is also not clearly endorsed by academics or students as a threshold concept in finance. This indicates that the role of statistics and modelling in finance needs to be made much more explicit. Some participants in the stage 1 focus groups (reported in self-identifying citation removed) argued that such concepts should be taught in ways that are not dependent on advanced mathematics skills such as via Microsoft Excel ${ }^{\mathrm{TM}}$ and programming languages, as shown to be effective by Kyng, Tickle and Wood (2011). However, this view was not universal with other participants arguing in favour of a more mathematically-based approach.

The limited reference to behavioural finance in the threshold concepts identified is not surprising given Coleman's (2013) argument that the neoclassical approach has been the basis of finance teaching. However, it may indicate that the concepts identified are based on what has been taught rather than what should be taught. And indeed, there is very little in Table 1 that is entirely new or unrelated to the finance topics and concepts identified in research in the 1980s and 1990s listed in the literature review. Notwithstanding this, this study identifies the threshold concepts that underpin theories and approaches rather than the theories and approaches themselves, and as such there is scope to refresh the finance 
curriculum by considering and teaching the threshold concepts from a behavioural perspective (Shiller, 2006). For example, the neoclassical view of market efficiency is that markets are efficient (the price of a stock is equal to its fundamental value) and cannot be beaten, but the behavioural finance view is that markets are not efficient - although they may be difficult to beat, notwithstanding that the assumption of efficiency is a useful heuristic to focus the analysis of pricing on other factors (Statman, 2008).

The majority ofOverall, the threshold concepts identified in this study are focused on discipline content knowledge. Some research has taken a broader view and identified more general or generic learning thresholds, for example subjectivity, uncertainty, contextualised meaning in accounting (Lucas and Mladenovic, 2006, 2007) and thinking like a mathematician or critically in engineering (Galligan et al., 2010; Worsley, 2011). Although more general and generic thresholds did arise in this research (mathematics and other more generic skills identified in the original focus group with academics and the student data), because they were not the focus of this study, they were not further explored as thresholds in finance.

The inclusion of more generic skills and more qualitative behavioural finance perspectives in the finance curriculum/learning and teaching finance is essential to prepare students for roles as finance practitioners. The failure of higher education programs to adequately prepare students for professional roles, particularly in relation to generic skills, is a common complaint of industry (Freeman et al., 2008). The importance of more generic skills, as opposed to discipline-specific knowledge, is reflected in graduate learning standards such as the Academic Learning Standards for Finance in the Australian Higher Education Context (Finance Learning Standards Working Party Australian Business Deans Council, 2014) which list application, judgement, communication, teamwork and reflection alongside knowledge. Furthermore, finance practitioners criticise the neoclassical finance theory which is the focus of finance programs as being of limited use in practice because the data required are not available, it does not work and it ignores more valuable qualitative data that is available (Coleman, 2013). Baillie et al. (2012) emphasise the importance of linking threshold concepts with threshold capabilities to equip students with the capabilities required to act effectively in professional roles, as demonstrated in the work of Male et al. (2015) in relation to engineering students and critical thinking skills. 


\section{Threshold concepts as a theoretical framework}

This research both supports and informs threshold concepts as a theoretical framework to inform learning and teaching (in finance) and the transformative, integrative, irreversible and troublesome characteristics of threshold concepts. Motivated by the relative newness of threshold concepts and the limited research into threshold concepts in finance, in stage 2 of the study the views of finance academics as to the potential of threshold concept theory to inform learning and teaching in finance were sought. Most finance academics surveyed rated the potential of threshold concepts to inform curriculum design and learning and teaching in finance highly, even if they as academics had no or limited exposure to the threshold concepts framework prior to the survey (self-identifying citation removed). Thus, the research provides evidence in support of the appeal (Barradell, 2013) and acceptance (Baillie et al., 2012) of threshold concepts.

The transformative, integrative, irreversible and troublesome characteristics were used in stage 2 to analyse and verify the proposed threshold concepts from stage 1 . At the same time, this approach has a reciprocal effect, in that it provides evidence as to the extent to which each of the four characteristics is associated with a concept being a threshold concept. The characteristic most strongly associated with a concept being a threshold concept in finance is the integrative characteristic, followed by the transformative and irreversible characteristics (self-identifying citation removed). This finding in relation to the integrative characteristic is particularly relevant for relatively new disciplines that have evolved from other disciplines, such as finance, where the discipline boundaries might be unclear. This is because, according to Davies and Mangan (2007), integration is associated with the definition of the boundaries of a discipline, such that the higher the integration, the clearer the discipline boundaries are. Thus, threshold concept theory through the integrative characteristic provides a way to define and delineate a discipline. Overall, this research supports Davies and Mangan (2007) in that the transformative, integrative and irreversible characteristics are the "primary" characteristics of threshold concepts.

Interestingly, the troublesome characteristic seems to have no clear relationship with a concept being a threshold concept in finance and perceptions of the troublesome characteristic are somewhat varied in the quantitative data (self-identifying citation removed). There appear to be three concerns with the troublesome characteristic. Firstly, a concept may be troublesome but not necessarily a threshold concept (Barradell, 2013) as per the statistics 
concepts in this research. Secondly, the "troublesomeness" may be due to other factors (Quinlan et al., 2013), as one of the participants in this research wrote:

"It is hard to judge the difficulty of a concept when it is being lectured as students may either find the concept difficult or the lecturer's explanations insufficient."

Thirdly, the "troublesomeness" may not be due to the difficulty of the concept, but rather due to the significant (conceptual and ontological) change brought about in the student (Land et al., 2014). Thus, academics, having gone through and reconciled themselves to this change, may have lost sight of troublesomeness. Similarly, academics tended not to endorse basic concepts as threshold concepts in this study, despite the fact that it is these concepts that are most likely to be transformative for students. This is perhaps because, having gone through the ontological shift, academics lose sight of the significance of such basic concepts and possibly even the concept itself.

Finally, by focusing on the conceptual knowledge that underpins mastery in a discipline, as discussed above specifically in relation to finance, threshold concept theory perhaps focuses on what is most static and constant in a discipline at the expense of innovation and the future needs of the discipline. Thus overall, whilst this study provides evidence in support of threshold concept theory and its use in curriculum design and learning and teaching, its focus on essential conceptual discipline knowledge and the subjectivity involved in the perception of the characteristics are factors which need to be taken into account when using threshold concept theory to investigate and inform curricula.

\section{Threshold concepts as research methodology}

Following Cousin's (2009) description of threshold concept research, the study was originally conceived as primarily qualitative, with data collected in focus groups and semi-structured interviews with finance academics and students. However, this approach does not take into account the fact that although qualitative research is well established and accepted in education, some disciplines, of which finance is one, place more emphasis on quantitative research. As the study progressed, the need to take into account the preferred research approach in finance, in part led to the adoption of more quantitative methods to validate the results of the qualitative research. This shift in approach was compounded by difficulties in getting sufficient discursive data from finance students. Thus, the collaboration between discipline specialists, educational researchers and students that is a feature of threshold 
concepts research (Cousin, 2009) may require the research methodology to be adapted and extended for the discipline. However, these adjustments and outcomes can inform and develop threshold concepts research methodology, as well as adding rigour to the theory by testing it in new ways.

Threshold concepts research is described by Cousin (2009) as a form of transactional curriculum inquiry, and hence the focus is on the concepts that academics identify as fundamental to the discipline, how students perceive these concepts and what curriculum design interventions are required to teach the concepts. However, this approach does not involve reference to industry practitioners, which is a significant omission for a vocational degree such as finance. Some finance industry practitioners are critical of the predominately neoclassical finance theory taught at universities (Coleman, 2013), and their involvement in threshold concept research would be a way to investigate and address the disjunction between what academics teach and the needs of the industry. This study therefore supports the argument of Barradell (2013) that transactional curriculum inquiry needs to be extended to include the professional community.

Threshold concepts methodology emphasises the role of discipline specialists in exploring the threshold concepts that are fundamental to a grasp of their own discipline (Cousin, 2009). However, when the discipline being researched involves enabling disciplines, such as mathematics in finance, the research should also involve academics from the enabling discipline. This would ensure that the contribution the enabling discipline makes to the threshold conceptual knowledge of the discipline being researched is more explicitly and comprehensively investigated. Whilst this study has explored and added clarity to the role of mathematics, and statistics as a types of mathematics, in finance and the extent to which mathematics concepts are threshold concepts in finance, it has only done so from the point of view of finance educators and would have benefited from the expertise of mathematics educators, particularly in relation to defining and developing mathematics skills in other disciplines. Furthermore, being involved in threshold concepts research would provide academics from enabling disciplines with additional insights into the perspectives of academics and students in relation to developing skills in the enabling discipline.

\section{Conclusion}

Finance is a relatively new discipline and highly interdisciplinary, involving economics, accounting and, traditionally, mathematics and statistics (Finance Learning Standards 
Working Party Australian Business Deans Council, 2014). It might be anticipated that the discipline boundaries of finance are rather unclear, which is partly why the bounded characteristic of threshold concept theory is not explored in this research. However, an unexpected finding of the research is the extent to which finance threshold concepts are associated with the integrative characteristic, which, according to Davies and Mangan (2007), indicates clear discipline boundaries. Finance has coalesced into an agreed and integrated set of concepts. Further research into the integration of finance threshold concepts, for example using concepts maps as discussed in Quinlan et al. (2013), offers a way to define, describe and distinguish finance as a discipline.

The study indicates that there is scope for threshold concepts to be made much more explicit to students in the design and delivery of the finance curriculum. Given that students were asked about important rather than threshold concepts in finance, the extent to which students experience the concepts identified here as threshold concepts could be further investigated, using the threshold concepts framework explicitly with more discursive data. As well as testing specific concepts, such research would provide a different perspective on characteristics associated with threshold concepts, particularly the troublesome and transformative characteristics which may be understated by academics. The difficulties in conducting research with students experienced in this study indicates that further research with students might be best undertaken as action research (Cousin, 2009) embedded in pedagogical practices, for example, threshold concepts expressed and made apparent to students in "pedagogical content knowledge” (PCK) as suggested by Shinners-Kennedy and Fincher (2013). Since pedagogical practices are learning and teaching activities for students, this approach avoids the problem (ethical and practical) of trying to get students to give up their time to participate in research which they may perceive as having little direct benefit to themselves.

The research also provides quantitative evidence that threshold concept theory is a valid theoretical framework, particularly the transformative, integrative and irreversible characteristics, perceived by finance academics as being helpful to learning and teaching in finance. The study does not investigate the bounded characteristic, nor discursive, reconstitutive and liminal aspects of the threshold concepts framework which are increasingly discussed in the literature (Barradell, 2013; Flanagan, 2015; Land et al., 2014). Although this study is focused on finance it shows the potential of threshold concepts to define and describe 
a discipline in terms of its boundaries and the role of key interdisciplinary knowledge, such as mathematics and statistics.

In relation to threshold concepts as a research methodology, the study demonstrates that threshold concepts research itself is interdisciplinary, and that whilst conducting threshold concepts research may require accommodating different research paradigms, this is likely to result in original and novel approaches and outcomes. However, without the involvement of industry the outcomes of threshold concept research may identify what is required to complete educational programs successfully, rather than what is required to act effectively in professional roles. In addition, in order to achieve the latter ${ }_{2}$ threshold concepts research needs to extend beyond highly discipline specific threshold concepts, as have been the primary focus of this research, to more general or generic, and perhaps more significant and transformative, learning thresholds, as has have been the focus in some threshold concepts research. 


\section{References}

Baillie, C., Bowden, J.A. and Meyer, J.H.F. (2013), “Threshold capabilities: threshold concepts and knowledge capability linked through variation theory”, Higher Education, Vol. 65 No. 2, pp. 227-246.

Bakker, A., Kent, P., Noss, R., Hoyles, C. and Bhinder, C. (2006), “'It’s not just magic!’: learning opportunities with spreadsheets in the financial sector”, in Hewitt, D. (Ed.), Proceedings of the British Society for Research into Learning Mathematics, Vol. 26, pp. 17-22.

Balachandran, B., Skully, M., Tant, K. and Watson, J. (2006), “Australian evidence on student expectations and perceptions of introductory business finance”, Accounting \& Finance, Vol. 46 No. 5, pp. 697-713.

Barradell, S. (2013), "The identification of threshold concepts: a review of theoretical complexities and methodological challenges”, Higher Education, Vol. 65 No. 2, pp. 265-276.

Berry, T.D. and Farragher, E.J. (1987), "Survey of introductory financial management courses”, Journal of Financial Education, Vol. 16, pp. 65-72.

Bourner, T., Greener, S. and Rospigliosi, A. (2009), “Mathematics students' next steps after graduation”, International Journal of Mathematical Education in Science and Technology, Vol. 40 No. 6, pp. 777-793.

Coleman, L. (2013), "Why finance theory fails to survive contact with the real world: a fund manager perspective”, Critical Perspectives on Accounting, Elsevier Ltd, Vol. 25 No. 3, pp. 226-236.

Cooley, P. and Heck, J. (1996), "Establishing benchmarks for teaching the undergraduate introductory course in financial management”, Journal of Financial Education, Vol. 22, pp. 1-10.

Cousin, G. (2006), “An introduction to threshold concepts”, Planet, No. 17, pp. 4-5.

Cousin, G. (2009), Strategies for Researching in Higher Education: An Introduction to Contemporary Methods and Approaches, Routledge, New York and London.

Davies, P. and Mangan, J. (2005), "Recognising threshold concepts: an exploration of different approaches", European Association in Learning and Instruction Conference (EARLI) August 23 - 37th 2005, Vol. 44, Nicosia, Cyprus, pp. 1-18.

Davies, P. and Mangan, J. (2007), "Threshold concepts and the integration of understanding in economics”, Studies in Higher Education, Vol. 32 No. 6, pp. 711-726.

Davies, P. and Mangan, J. (2008), "Embedding threshold concepts: from theory to pedagogical principles to learning activities”, in Land, R., Meyer, J.H.F. and Smith, J. (Eds.), Threshold Concepts within the Disciplines, Sense, Rotterdam, pp. 37-50.

Deloitte. (2013), Positioning for Prosperity? Catching the next Wave, available at: http://www.deloitte.com/view/en_AU/au/news-research/luckycountry/prosperity-nextwave/index.htm.

Diamond, R. V. (2011), “Analysis of assessment data from statistics courses: grade distributions, surface learning and threshold concepts", Social Science Research Network, available at: http://papers.ssrn.com/sol3/papers.cfm?abstract_id=1890833 (accessed 11 February 2016).

Diamond, R. V. (2014), “Learning and trusting cointegration in statistical arbitrage”, Social Science Research Network, August, available at: http://ssrn.com/abstract=2220092 (accessed 11 February 2016).

Diamond, R. V. and Smith, H.J. (2011), “Threshold concepts: a disciplinary enquiry in quantitative 
finance”, Social Science Research Network, July, available at: http://ssrn.com/abstract=1890837 (accessed 2 February 2016).

Finance Learning Standards Working Party Australian Business Deans Council. (2014), Academic Learning Standards for Finance in the Australian Higher Education Context, Deakin, Australia.

Flanagan, M. (2015), “Threshold concepts: undergraduate teaching, postgraduate training and professional development - a short introduction and bibliography”, available at: http://www.ee.ucl.ac.uk/ mflanaga/thresholds.html (accessed 11 February 2016).

Frankfurter, G.M. (2006), “The Theory of Fair Markets (TFM) toward a new finance paradigm”, International Review of Financial Analysis, Vol. 15 No. 2, pp. 130-144.

Freeman, M., Hancock, P., Simpson, L., Sykes, C., Petocz, P., Densten, I. and Gibson, K. (2008), Business as Usual: A Collaborative and Inclusive Investigation of Existing Resources, Strengths, Gaps and Challenges to Be Addressed for Sustainability in Teaching and Learning in Australian University Business Faculties, Sydney, Australia, available at: file://D:/UsersData/mq20021280/Downloads/Grants_DBI_ABDC-Freeman-Business-FinalReport_March27_2008 (5).pdf.

Galligan, L., Wandel, A.P. and Hartle, R.T. (2010), "Scaffolding distance learning in mathematics for engineering: identifying key troublesome knowledge”, STEM in Education Conference, 26 \& 27 November 2010 - Queensland University of Technology, Brisbane, Australia, available at: http://eprints.usq.edu.au/19325/2/Galligan_Wandel_Hartle_STEM_2010_AV.pdf.

Gup, B. (1994), “The five most important finance concepts: a summary”, Financial Practice and Education, pp. 106-110.

Halliday, M.A.K. and Hasan, R. (1976), Cohesion in English, Longman, London.

Halliday, M.A.K. and Matthiessen, C.M.I.M. (1999), Construing Experience through Meaning: A Language-Based Approach to Cognition, Cassell, London.

Jackling, B. and Sullivan, C. (2007), "Financial planners in Australia: an evaluation of gaps in technical and behavioral skills”, Financial Services Review, Vol. 16 No. 3, pp. 211-228.

Johnson, R.B. and Onwuegbuzie, A.J. (2004), "Mixed methods research: a research paradigm whose time has come”, Educational Researcher, Vol. 33 No. 7, pp. 14-26.

Kent, P., Noss, R., Guile, D., Hoyles, C. and Bakker, A. (2007), “Characterizing the Use of Mathematical Knowledge in Boundary-Crossing Situations at Work”, Mind, Culture, and Activity, Vol. 14 No. 1-2, pp. 64-82.

Krishnan, V.S., Bathala, C.T., Bhattacharya, T. and Ritchey, R. (1999), “Teaching the introductory finance course: what can we learn from student perceptions and expectations?”, Financial Practice and Education, pp. 70-83.

Kyng, T., Tickle, L. and Wood, L.N. (2011), “Graduates' use of technical software in financial services”, in Lau, M. and Sugden, S. (Eds.), Applications of Spreadsheets in Education the Amazing Power of a Simple Tool, Bentham Science Publishers, Hilversum, The Netherlands, pp. 241-260.

Lai, M.M., Kwan, J.H., Kadir, H.A., Abdullah, M. and Yap, V.C. (2009), "Effectiveness, teaching, and assessments: survey evidence from finance courses", Journal of Education for Business, Vol. 85 No. 1, pp. 21-29.

Lakshmi, G. (2013), “An exploratory study on cognitive skills and topics focused in learning objectives of finance modules: a UK perspective”, Accounting Education, Vol. 22 No. 3, pp. 233-247.

Land, R., Rattray, J. and Vivian, P. (2014), “Learning in the liminal space: a semiotic approach to 
threshold concepts”, Higher Education, Vol. 67 No. 2, pp. 199-217.

Lucas, U. and Mladenovic, R. (2006), "Developing new world views: Threshold concepts in introductory accounting”, in Meyer, J.H.F. and Land, R. (Eds.), Overcoming Barriers to Student Understanding: Threshold Concepts and Troublesome Knowledge, Routledge - Taylor Francis Group, London and New York, pp. 100-114.

Macquarie University. (2012), Review of the Bachelor of Applied Finance, Sydney, Australia.

Male, S., Baillie, C., Macnish, C., Leggoe, J., Hancock, P., Alam, F., Crispin, S., et al. (2015), "Student experiences of threshold capability development in an engineering unit with intensive mode", Proceedings of the 26th Annual Conference of the Australasian Association for Engineering Education - AAEE2015, 6-9 December, Geelong, Australia, pp. 1-10.

Matthiessen, C.M.I.M. (2004), The Semantic System of RELATIONAL EXPANSION: Rhetorical Structure Theory Revised, Sydney, Australia.

McWilliams, V. and Pantalone, C. (1994), "Structuring the finance curriculum: a survey”, Financial Practice and Education, pp. 37-47.

Meyer, J.H.F. and Land, R. (2003), “Threshold concepts and troublesome knowledge: linkages to ways of thinking and practising within the disciplines", in Rust, C. (Ed.), Improving Student Learning - Theory and Practice Ten Years on, Oxford Centre for Staff and Learning Development (OCSLD), Oxford, pp. 412-424.

Meyer, J.H.F. and Land, R. (2005), “Threshold concepts and troublesome knowledge (2): epistemological considerations and a conceptual framework for teaching and learning”, Higher Education, Vol. 49 No. 3, pp. 373-388.

Philippon, T. and Reshef, A. (2012), "Wages and human capital in the US financial industry: 19092006”, Quarterly Journal of Economics, Vol. 127 No. November, pp. 1551-1609.

Quinlan, K.M., Male, S., Baillie, C., Stamboulis, A., Fill, J. and Jaffer, Z. (2013), “Methodological challenges in researching threshold concepts: a comparative analysis of three projects", Higher Education, Vol. 66 No. 5, pp. 585-601.

Shiller, R.J. (2006), "Tools for financial innovation : neoclassical versus behavioral finance", The Financial Review, Vol. 41 No. 1, pp. 1-8.

Shinners-Kennedy, D. and Fincher, S. (2013), "Identifying threshold concepts: from dead end to a new direction", Ninth Annual International ACM Conference on International Computing Education Research (ICER '13), ACM, New York, NY, USA, pp. 9-18.

Statman, M. (2008), “What is behavioral finance?”, in Fabozzi, F.J. (Ed.), Handbook of Finance, Vol. II, John Wiley \& Sons, Hoboken, NJ, pp. 79-84.

Wood, L.N., Mather, G., Petocz, P., Reid, A., Engelbrecht, J., Harding, A., Houston, K., et al. (2012), "University students' views of the role of mathematics in their future", International Journal of Science and Mathematics Education, Vol. 10 No. 1, pp. 99-119.

Worsley, S.R. (2011), “The big ideas in two large first level courses of undergraduate mathematics”, Mathematics: Traditions and [new] Practices, AAMT23/MERGA34, Alice Springs, Australia, pp. 839-845. 